九州大学学術情報リポジトリ

Kyushu University Institutional Repository

\title{
Continuous Modeling of Infiltration Rate for the Management of Sprinkler Irrigation
}

Wang, Guoqiang

College of Water sciences, Beijing Normal University

Xue, Baolin

Laboratory of Forest Ecosystem Management, Division of, Department of Forest \& Forest Products

Sciences, Graduate School of Bioresearch and Bioenvironmental Sciences, Kyushu University

Xue, Xiangshan

College of Water sciences, Beijing Normal University

Yu, Jingshan

College of Water sciences, Beijing Normal University

他

https://doi.org/10.5109/19544

出版情報 : 九州大学大学院農学研究院紀要. 56 (1)，pp. 157-161，2011-02. 九州大学大学院農学研究院 バージョン：

権利関係 : 


\title{
Continuous Modeling of Infiltration Rate for the Management of Sprinkler Irrigation
}

\author{
Guoqiang WANG ${ }^{1}$, Baolin XUE ${ }^{2}$, Xiangshan XUE ${ }^{1}$, Jingshan YU ${ }^{1 *}$ \\ and Kyoichi OTSUKI ${ }^{3}$
}

\author{
Laboratory of Ecohydrology, Division of Forest Sciences, Department of Agro-environmental Sciences, \\ Faculty of Agriculture, Kyushu University, Fukuoka 811-2415, Japan \\ (Received October 29, 2010 and accepted November 8, 2010)
}

\begin{abstract}
The spatially and temporally variable characteristics of soil infiltration process are a major physical constraint for the irrigated lands to achieve higher irrigation efficiencies. Substantial works have been directed towards developing state-dependent models to estimate the infiltration characteristics of soils, which are not suitable for continuous simulation of the infiltration process under complex rainfall or irrigation intensities. In this study, the time compression approximation (TCA) method is coupled with the Philip's infiltration equation, and the coupled infiltration model is extended beyond the ponding time to estimate the postponding infiltration process. An offset time is then introduced into the coupled infiltration model for solving the problems caused by the necessities of refreshing the state-dependent variables stepwisely. This simplifies the determination processes of the model's variables and amplifies its applicability under complex rainfall or irrigation intensities. By using the soil experimental data, the TCA based infiltration model shows good performance in predicting the cumulative infiltration. The deviation coefficients of the infiltration predictions range from $0.59 \%$ to $34.74 \%$, and the Nash coefficient of efficiency is calculated to be $82 \%$ for all the simulated results. This suggests that the proposed TCA based infiltration model could be suitable for the management of sprinkler irrigation.
\end{abstract}

Keywords: Infiltration; time compression approximation; Philip

\section{INTRODUCTION}

Surface irrigation is the most common method for irrigating crops and pastures. However, sprinkler irrigation has been getting popular in China due to its similarity to rainfall patterns, low cost, low energy requirements and improved aeration of the root zone. The infiltration rate is one of the dominant factors in determining the performance of sprinkler irrigation, and both spatial and temporal variations of the infiltration rate are a major physical constraint for achieving higher irrigation efficiencies (Shafique and Skogerboe, 1983). The importance to understand the infiltration characteristic has long been recognized and has received wide attention from various researchers, and the vertical infiltration into a deep and uniform soil has played a key role in these studies (Sivapalan and Milly, 1989; Poulovassilis et al., 1991; Raine et al., 1997). The estimate of the temporally variable infiltration rates requires an enormous computational burden because of the high temporal variability in rainfall rate. Therefore, how to estimate infiltration rate by switching the infiltration process from rainfall controlled condition to soil controlled condition is very important.

The time compression approximation (TCA) method

${ }^{1}$ College of Water sciences, Beijing Normal University, Xinjiekouwai Street 19, Beijing 100875, China

${ }^{2}$ Laboratory of Forest Ecosystem Management, Division of, Department of Forest \& Forest Products Sciences, Graduate School of Bioresearch and Bioenvironmental Sciences, Kyushu University, Fukuoka 811-2415, Japan

Laboratory of Ecohydrology, Division of Forest Sciences, Department of Agro-environmental Sciences, Faculty of Agriculture, Kyushu University, Fukuoka 811-2415, Japan

* Corresponding author (E-mail: jingshan@bnu.edu.cn) is used here for solving the infiltration rate under comlex rainfall (irrigation) rate. TCA was first introduced by Sherman (1943), and later used by several researchers in water balance modeling (Reeves and Miller, 1975; Eagleson, 1978; Milly, 1986; Famiglietti et al., 1992; Larsen et al., 1994; Salvucci and Entekhabi, 1994; Robinson and Sivapalan, 1995; Kim et al., 1996; Salvucci, 1997). The potential infiltration rate is usually defined as the maximum infiltration rate under ponded condition. The TCA assumes that the potential infiltration rate varies only with the volume of water infiltrated into the soil from the beginning until that time. Thus the potential infiltration rate depends on the cumulative infiltration within the given period of time regardless of its rainfall rate (Liu et al., 1998). Salvucci and Entekhabi (1994) compared the TCA method with the one rigorously defined flux concentration method. They used the latter to validate TCA method and found that the largest error of TCA in calculating cumulative infiltration was only 2.5\%. The main objectives of this paper are: (1) to propose a modified TCA method for continuous infiltration modelling without additional parameters; (2) to validate the proposed TCA method using the local experimental data.

\section{INFILTRATION MODEL}

TCA assumes that potential infiltration rate depends only on the initial soil moisture and the cumulative infiltration. Under this assumption, the potential infiltration rate $f(t)$ at time $t$, is expressed by the TCA equation $G_{T C A}$, which is a function of potential cumulative infiltration $F(t)$. 


$$
f(t)=G_{T C A}\{F(t)\}
$$

The actual infiltration rate $f^{*}(t)$ is the lesser of infiltration rate or the rainfall (irrigation) rate.

$$
f^{*}(t)=\operatorname{Min}\{f(t), P(t)\}
$$

This relation between actual and potential infiltration rate can be analyzed either by experiments or models. In this study, the Philip's equation was used to generate this relation. Philip (1957) expressed the potential infiltration rate as

$$
f(t)=0.5 S t^{-1 / 2}+c K_{s}
$$

where $S$ is the initial soil sorptivity, $K_{s}$ is the saturated hydraulic conductivity, and $c$ is a coefficient. $S$ depending on the soil water potential can be calculated from the equation given by Smith (1993).

$$
S^{2}=2\left(\theta_{s}-\theta_{i}\right) \int_{\theta_{i}}^{\theta_{s}} K(\theta)\left(\frac{d \phi}{d \theta}\right) d \theta
$$

where $\theta$ is soil water content, $\phi$ is soil water potential, $K$ is hydraulic conductivity, and the subscriptions of $i$ and $s$ represent the initial and saturated conditions respectively. $K(\theta)$ was assumed to fit Brooks and Corey model (1964) and $\phi(\theta)$ was calculated using Smith's equation as follows:

$$
\begin{aligned}
& K(\theta)=K_{s}\left\{\frac{\theta-\theta_{r}}{\theta_{s}-\theta_{r}}\right\}^{b+(a / \lambda)} \\
& \phi(\theta)=\phi_{b}\left\{\left(\frac{\theta-\theta_{r}}{\theta_{s}-\theta_{r}}\right)^{-(m / \lambda)}-1\right\}^{1 / m}
\end{aligned}
$$

where $\phi_{b}$ is the air entry soil water potential, $\theta_{r}$ is the residual soil water content, $a, b, m$ and $\lambda$ are dimensionless coefficients.

Under continuous rainfall (irrigation) rate, the actual infiltration rate should be equal to the rainfall (irrigation) rate and less than the potential infiltration rate for a while after rainfall start. After the actual infiltration rate becomes equal to the potential infiltration rate, it should remain equal to the rainfall (irrigation) rate for a while. Then, after certain time, the actual infiltration rate could become smaller than rainfall (irrigation) rate, and the ponding starts. In these processes, there are two impor-

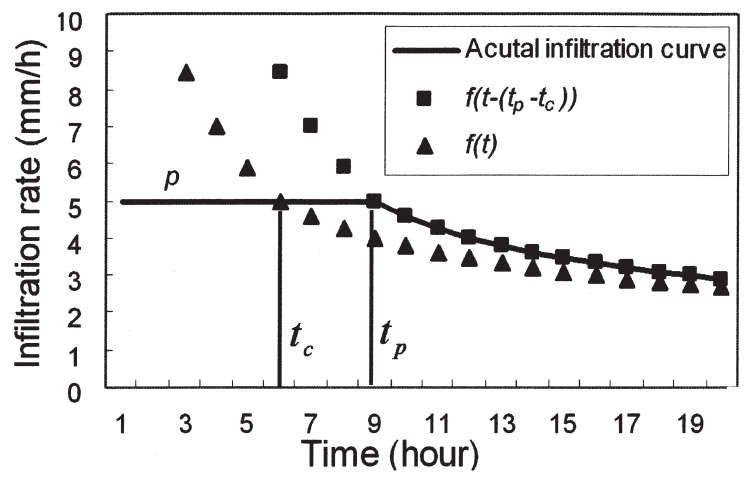

Fig. 1. Illustration of TCA based infiltration rate. tant time points. The one is the compressed time $t_{c}$ when the actual infiltration rate become equal to the potential infiltration rate. The other is the ponding time $t_{p}$, when the ponding starts (Fig. 1). With the Philip's equation, the compressed time $t_{c}$ can be derived by assuming the potential infiltration rate equals to the rainfall rate $p$.

$$
t_{c}=4 S^{-2} \cdot\left(p-c K_{s}\right)^{2}
$$

The potential cumulative infiltration, $F\left(t_{c}\right)$, under this assumption can be calculated to this time.

$$
F\left(t_{c}\right)=S \cdot t_{c}^{1 / 2}+c K_{s} \cdot t_{c}
$$

Ponding time is considered to be the boundary condition switching the infiltration process from rainfall controlled conditions to soil controlled conditions. Under TCA assumptions, ponding will occur at a time when the cumulative infiltration is equal to the total rainfall (irrigation) volume. Therefore, the ponding time can be solved as

$$
t_{p}=\frac{S^{2}}{4 p \cdot c K_{S}}\left\{\frac{p^{2}}{\left(p-c K_{s}\right)^{2}}-1\right\}
$$

Once ponding occurred, the actual infiltration should be less than the rainfall (irrigation) rate. We then used a relative time $t-\left(t_{p}-t_{c}\right)=t-t_{p}+t_{c}$ and calculated the actual infiltration rate at any time greater than $t_{p}$ by

$$
f^{*}(t)=f\left(t-t_{p}+t_{c}\right)=0.5 \cdot S \cdot\left(t-t_{p}+t_{c}\right)^{-1 / 2}+c K_{s}
$$

The above description solves the infiltration under constant rainfall (irrigation) rate. In case of variable rainfall (irrigation) rate, the similar TCA method can still be used, in which the ponding time $t_{p, i}$ under the rainfall rate $p_{i}$ at the time step $i$ is re-calculated for each time step.

$$
t_{p, i}=\frac{S \cdot\left(t_{c, i}\right)^{1 / 2}+c K_{s} \cdot t_{c, i}-F\left(t_{i-1}\right)}{p_{i}}
$$

Although the variability of $S$ is generally neglected, it is actually a time-dependent variable in Philip's equation. In each time step in which continuous rainfall (irrigation) rate is assumed within the time, $S$ should be re-calculated. However, it is difficult to realize because the variables to calculate $S$ are also changing temporally. In this paper, a new concept of offset time $t_{f, i}$ was introduced to solve this problem. Since, the actual infiltration rate at the end of the time step must be equal to the one at the beginning of the next time step. Thus $t_{f, i}$ can be represented by relating the corresponding time for two time steps under the ponded conditions.

$$
f\left(t_{i+1}+t_{f, i}\right)=f\left(t_{i}-t_{p, i}+t_{c, i}\right)
$$

Combing Eq. (12) with Eq. (3), Eq. (7) and Eq. (11), the offset time can be solved as

$$
t_{f, i}=\frac{2 c K_{s} F\left(t_{i-1}\right)+S^{2}-S \sqrt{4 c K_{s} F\left(t_{i-1}\right)+S^{2}}}{2\left(c K_{s}\right)^{2}}
$$


Therefore, under variable rainfall (irrigation) rate, there are three possible situations of the infiltration

$$
\begin{aligned}
& \Delta t \leq t_{p, i}: \text { no ponding occurs } \\
& \Delta t>t_{p, i}: \text { ponding occurs }
\end{aligned}
$$$$
t_{p, i}<0 \text {, : ponding happened at the exact beginning. }
$$
where $\Delta t$ is the time step.

All three possible expressions are summarized as a function of the infiltration volume during a given time step.

$$
\begin{aligned}
& \Delta F\left(t_{i}\right)=p_{i} \cdot \Delta t \quad \text { if } p_{i} \leq c K_{S} \\
& \Delta F\left(t_{i}\right)=c K_{S} \cdot \Delta t+S \cdot\left(\sqrt{\Delta t+t_{f, i}}-\sqrt{t_{f, i}}\right) \text { if } p_{i}>c K_{S}, t_{p, i}<0 \\
& \Delta F\left(t_{i}\right)=p_{i} \cdot t_{p, i}+c K_{S} \cdot\left(\Delta t-t_{p, i}\right) \\
& \left.+S \cdot\left(\sqrt{\Delta t-\left(t_{p, i}-t_{c, i}\right.}\right)-\sqrt{t_{c, i}}\right) \quad \text { if } \quad p_{i}>c K_{S}, t_{p, i} \geq 0
\end{aligned}
$$

\section{MODEL EVALUATION}

Soil experiments were conducted by Yu et al. (2006) in the two cultivated soils types (Acrisol and Cambisol) at the six sites. The soils at the Site-1, 2 and 3 were the

\begin{tabular}{|c|c|c|c|c|c|c|}
\hline \multirow{2}{*}{$\begin{array}{l}\text { Site } \\
\text { No. }\end{array}$} & \multicolumn{4}{|c|}{ Mechanical composition (\%) } & \multirow{2}{*}{$\begin{array}{l}\text { Bulk density } \\
\quad\left(\mathrm{g} / \mathrm{cm}^{3}\right)\end{array}$} & \multirow{2}{*}{$\begin{array}{c}K s \\
(\mathrm{~mm} / \mathrm{h})\end{array}$} \\
\hline & $2-0.5 \mathrm{~mm}$ & $0.5-0.05 \mathrm{~mm}$ & $0.05-0.002 \mathrm{~mm}$ & $<0.002 \mathrm{~mm}$ & & \\
\hline 1 & 1.0 & 23.5 & 33.6 & 46.4 & 1.37 & 57.06 \\
\hline 2 & 1.0 & 28.8 & 34.4 & 35.8 & 1.19 & 36.51 \\
\hline 3 & 4.7 & 29.9 & 34.5 & 30.9 & 1.33 & 48.64 \\
\hline 4 & 1.7 & 61.0 & 19.8 & 17.5 & 1.43 & 36.86 \\
\hline 5 & 0.5 & 64.3 & 15.7 & 19.5 & 1.50 & 32.51 \\
\hline 6 & 0.8 & 63.3 & 19.9 & 16.0 & 1.54 & 85.14 \\
\hline
\end{tabular}
cultivated Acrisol while the soils at Site-4, 5 and 6 were

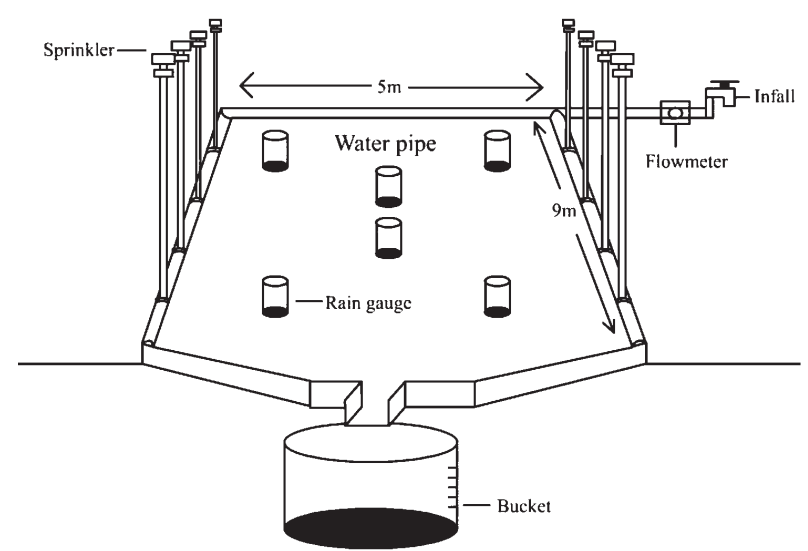

\begin{tabular}{|c|c|c|c|c|c|c|}
\hline $\begin{array}{l}\text { Site } \\
\text { No. }\end{array}$ & $\begin{array}{l}\text { Rainfall } \\
\text { No. }\end{array}$ & $\begin{array}{l}\text { Rainfall intensity } \\
(\mathrm{mm} / \mathrm{h})\end{array}$ & $\begin{array}{l}\text { Surface runoff } \\
\text { (mm) }\end{array}$ & $\begin{array}{c}\text { Runoff } \\
\text { coefficient }\end{array}$ & $\begin{array}{c}\theta_{i} \\
(\mathrm{~g} / \mathrm{kg})\end{array}$ & $\begin{array}{c}\theta_{s} \\
(\mathrm{~g} / \mathrm{kg})\end{array}$ \\
\hline \multirow[t]{3}{*}{1} & 1 & 58.1 & 13.75 & 0.24 & 153.6 & 219.1 \\
\hline & 2 & 51.8 & 23.92 & 0.46 & & \\
\hline & 3 & 45.2 & 24.45 & 0.54 & & \\
\hline \multirow[t]{3}{*}{2} & 1 & 59.6 & 20.65 & 0.35 & 157.7 & 205.0 \\
\hline & 2 & 56.3 & 31.37 & 0.58 & & \\
\hline & 3 & 53.3 & 32.09 & 0.60 & & \\
\hline \multirow[t]{3}{*}{3} & 1 & 58.0 & 2.14 & 0.04 & 184.6 & 202.7 \\
\hline & 2 & 57.3 & 12.79 & 0.22 & & \\
\hline & 3 & 60.4 & 21.89 & 0.36 & & \\
\hline \multirow[t]{3}{*}{4} & 1 & 61.7 & 22.06 & 0.36 & 112.6 & 158.9 \\
\hline & 2 & 57.3 & 32.49 & 0.57 & & \\
\hline & 3 & 61.6 & 33.83 & 0.55 & & \\
\hline \multirow[t]{3}{*}{5} & 1 & 57.7 & 26.94 & 0.47 & 92.9 & 170.3 \\
\hline & 2 & 55.1 & 33.12 & 0.60 & & \\
\hline & 3 & 56.4 & 37.42 & 0.66 & & \\
\hline \multirow[t]{3}{*}{6} & 1 & 60.2 & 16.38 & 0.27 & 120.1 & 169.8 \\
\hline & 2 & 61.6 & 28.79 & 0.47 & & \\
\hline & 3 & 59.3 & 28.63 & 0.48 & & \\
\hline
\end{tabular}

Fig. 2. Experimental set up used for soil testing (Yu et al., 2006).

Table 1. Soil properties of topsoils at the experimental sites (Yu et al., 2006)

Table 2. Soil experimental conditions and observed results at the experimental sites 
cultivated Cambisol. Soil properties at the six sites were measured at the topsoils $(0-20 \mathrm{~cm})$ and subsoils (20$40 \mathrm{~cm}$ ). Table 1 shows the soil properties of topsoils and the corresponding saturated hydraulic conductivities, which are used in model evaluation.

A sprinkling rainfall simulator was used to generate rainfall with varying intensities; the rainfall simulator has an intensity ranging from 20 to $100 \mathrm{~mm} / \mathrm{h}$. Three rainfall simulation events were conducted on each site respectively. These events have one-hour durations and a onehour interval between two events (Fig. 2). In all events, the rain was produced at an average intensity of $60 \mathrm{~mm} / \mathrm{h}$ over an area of $45 \mathrm{~m}^{2}$ at a height of $3 \mathrm{~m}$; plant residues at the surface were removed before the experiment ( $\mathrm{Yu}$ et al., 2006).

At each site, the topsoil $(0-20 \mathrm{~cm})$ and subsoil $(20-$ $40 \mathrm{~cm}$ ) were sampled for chemical and physical analysis. Prior to each event, the initial soil water contents and bulk densities of the topsoil and subsoil were measured. Surface runoff was sampled at 10 min intervals. Table 2 shows the experimental conditions and the observed results at the experimental sites (Yu et al., 2006). The results show that the average runoff coefficient at Site-5 was the highest, while Site-2 and Site- 4 were slightly lower, which reflects the different infiltration level at each experimental site. The low initial water content at Site-5 caused sealing at the surface soil, which affects runoff coefficient.

The artificial rainfall rates by rainfall simulator were cited as input data to the modified TCA method. The measured and estimated infiltrations rates are compared in Table 3 and Fig. 3. It is shown that the modified TCA

Table 3. Comparison between measured and predicted infiltration rates at the experimental sites

\begin{tabular}{|c|c|c|c|c|}
\hline \multirow{2}{*}{$\begin{array}{l}\text { Site } \\
\text { No. }\end{array}$} & \multirow{2}{*}{ Rainfall No. } & \multicolumn{2}{|c|}{ Infiltration rate $(\mathrm{mm} / \mathrm{h})$} & \multirow{2}{*}{ Deviation (\%) } \\
\hline & & Measured & Predicted & \\
\hline \multirow[t]{3}{*}{1} & 1 & 44.35 & 42.58 & 3.99 \\
\hline & 2 & 27.88 & 27.71 & 0.61 \\
\hline & 3 & 20.75 & 24.90 & 20.00 \\
\hline \multirow[t]{3}{*}{2} & 1 & 38.95 & 32.92 & 15.48 \\
\hline & 2 & 24.93 & 27.71 & 11.15 \\
\hline & 3 & 21.21 & 24.86 & 17.21 \\
\hline \multirow[t]{3}{*}{3} & 1 & 55.86 & 45.03 & 19.39 \\
\hline & 2 & 44.51 & 42.17 & 5.26 \\
\hline & 3 & 38.51 & 36.33 & 5.66 \\
\hline \multirow[t]{3}{*}{4} & 1 & 39.64 & 37.30 & 5.90 \\
\hline & 2 & 24.81 & 27.97 & 12.74 \\
\hline & 3 & 27.77 & 29.95 & 7.85 \\
\hline \multirow[t]{3}{*}{5} & 1 & 30.76 & 29.49 & 4.13 \\
\hline & 2 & 21.98 & 24.86 & 13.10 \\
\hline & 3 & 18.98 & 25.57 & 34.72 \\
\hline \multirow[t]{3}{*}{6} & 1 & 43.82 & 38.56 & 12.00 \\
\hline & 2 & 32.81 & 36.37 & 10.85 \\
\hline & 3 & 30.67 & 28.01 & 8.67 \\
\hline
\end{tabular}

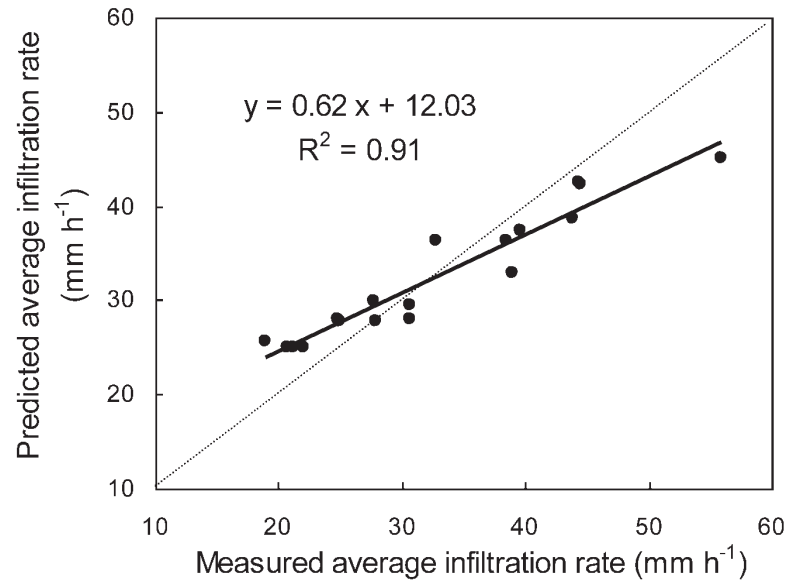

Fig. 3. Comparison of the measured and predicted infiltration rates.

method tends to overestimate in the low infiltration rate range (under $30 \mathrm{~mm} / \mathrm{h}$ ) and underestimate in the high infiltration rate range (over $30 \mathrm{~mm} / \mathrm{h}$ ). Of all the estimated actual infiltration rates, the deviation coefficients range from $0.59 \%$ to $34.74 \%$, and the variation of differences was found to be closely related to the rainfall rates. Generally, high rainfall rate caused high infiltration volume, which leads to low difference deviation. The root mean square error is $426 \mathrm{~mm} / \mathrm{h}$ and the Nash-Sutcliffe (Nash) coefficient of efficiency is $82 \%$ for all the estimated results, which is acceptable for the on-site infiltration prediction.

In infiltration modelling, the initial soil water content $\theta_{i}$ is one of the most important parameters, which greatly influences the final results. Meanwhile, the values of $\theta_{i}$ may vary from event to event depending on the initial condition settings. To assign different values to $\theta_{i}$ for all events, long-term soil water content measurement is needed, which decreases the applicability of infiltration modelling. In this study, by introducing the modified TCA method in which only initial soil conditions either observed or calibrated based literature values are required. To distinguish the difference of $\theta_{i}$, the first rainfall simulation is generally important for the prediction precision of the infiltration model.

\section{CONCLUSIONS}

TCA method provides an adequate tool for description transition of state dependent infiltration processes from rainfall control to soil control. In TCA method, the cumulative infiltration can be easily calculated, therefore, the major error in estimating infiltration come from the error in estimating the ponding time $t_{p}$. In this study, we suggest a modified TCA method by introducing the newly proposed offset time into TCA method, in which the exact ponding time can be calculated to improve the estimate of postponding infiltration process. Hence there would be less error in estimating the cumulative infiltration, which is validated using the experimental data. On the basis of results and analysis this paper presented, the modified TCA method is not only more realistic than standard TCA method using cumulative infil- 
tration rather than infiltration rates but more accurate as well in predicting the cumulative infiltration. The TCA method has the potential for use in the management of sprinkler irrigation.

\section{ACKNOWLEGEMENTS}

This research is supported by National Natural Science Foundation of China (Grant No. 41001155) and Kyushu University Research Institute for East Asia Environment.

\section{REFERENCES}

Brooks K. and A. Corey 1964 Hydraulic properties of porous media. Hydrology paper No. 3, Colorado State University Press

Eagleson P. S. 1978 Climate, soil, and vegetation, 5, A derived distribution of storm surface runoff. Water Resour. Res., 14(5): $741-748$

Famiglietti J. S., E. F. Wood, M. Sivapalan and D. J. Thongs 1992 A catchment scale water balance model for FIFE. J. Geophys. Res., 97(D17): 18997-19007

Kim C. P., J. N. M. Stricker and P. J. J. F. Torfs. 1996 An analytical framework for the water budget of the unsaturated zone. Water Resour. Res., 32(12): 3475-3484

Larsen J. E., M. Sivapalan, N. A. Coles and P. E. Linnet 1994 Similarity analysis of runoff generation processes in real-world catchments. Water Resour. Res., 30(6): 1641-1652

Liu M. C., J. Y. Parlange, M. Sivapalan and W. Brutsaert 1998 A note on the time compression approximation. Water Resour. Res., 34(12): 3683-3686

Milly P. C. D. 1986 An event-based simulation model of moisture and energy fluxes at a bare soil surface. Water Resour. Res., 22(12): 1680-1692
Philip J. R. 1957 The theory of infiltration: 1. The infiltration equation and its solution. Soil Science 83: 435-448

Poulovassilis A. P., P. Kerkides, S. Elmaloglou and I. Argyrokastritis 1991 An investigation of the relationship between ponded and constant flux rainfall infiltration. Water Resour. Res., 27(7) 1403-1409

Raine S. R., D. J. McClymont and R. J. Smith 1997 The development of guidelines for surface irrigation in areas with variable infiltration. In: Proceedings of Australian Society of Sugercane Technologists, pp. 293-301

Reeves M. and E. E. Miller 1975 Estimating infiltration for erratic rainfall. Water Resour. Res., 11(1): 102-110

Robinson J. S. and M. Sivapalan 1995 Catchment-scale runoff generation model by aggregation and similarity analyses. Hydrol. Process., 9: 555-574

Salvucci G. D. and D. Entekhabi 1994 Equivalent steady soil moisture profile and the time compression approximation in water balance modeling. Water Resour. Res., 30(10): 2737-2749

Salvucci G. D. 1997 Soil and moisture independent estimation of stage-two evaporation from potential evaporation and albedo or surface temperature. Water Resour. Res., 33(1): 111-122

Shafique M. S. and G. V. Skogerboe 1983 Impact of seasonal infil tration function variation on furrow irrigation performance. In: Advances in infiltration, proceedings of national conference on advances in infiltration. ASAE, St. Joseph, pp. 292-301

Sherman L. K. 1943 Comparison of F-curves derived by the methods sharp and Holtan and of Sherman and Mayer. Transactions of the American Geophysical Union, 24: 465-467

Sivapalan M. and P. C. D. Milly. 1989 On the relationship between the time condensation approximation and the flux-concentration relation. J. Hydrol., 105: 357-367

Smith R. E., C. Corradini and F. Melone 1993 Modeling infiltration for multistorm runoff events. Water Resour. Res., 29 (1): $133-144$

Yu D. S., X. Z. Shi and D. C. Weindorf 2006 Relationships between permeability and erodibility of cultivated Acrisols and Cambisols in subtropical China. Pedosphere, 16(3): 304-311 
